\title{
As noções de acontecimento enunciativo e de acontecimento discursivo: um othar sobre o discurso politico
}

The notions of enunciative event and discursive event: a view upon the political discourse

Ercília Ana Cazarin Universidade Católica de Pelotas, Pelotas, RS, Brasil Gesualda dos Santos Rasia Universidade Federal do Paraná, Curitiba, PR, Brasil

Resumo: 0 texto situa-se no campo do discurso político e, teoricamente sustentado na Análise do Discurso, ocupa-se em compreender se a posse de Dilma Rousseff na presidência do Brasil (2011) se constituiu como um acontecimento discursivo ou enunciativo. A questão que nos instiga é se o fato de ela ter sido a primeira mulher a ocupar o lugar da presidência, revestido de características também singulares, permitir-nos-ia afirmar que estaríamos diante de um acontecimento discursivo nos moldes do que preceitua Pêcheux (1990) em Discurso: estrutura ou acontecimento, ou se se constituiria como um acontecimento enunciativo nos moldes do que vem sendo trabalhado por Indursky desde 2002.

Palavras-chave: Acontecimento discursivo. Acontecimento enunciativo. Posse de Dilma Rousseff. Análise do Discurso.

Abstract: The text is placed in the field of political discourse and, theoretically grounded on the Discourse Analysis. It is concerned whether the understanding Dilma Rouseff inauguration as president of Brazil (2011) constitutes itself as either a discursive event or an enunciative one. The question that drives us is whether the fact of being the first woman to ever occupy the presidency, lined also with singular features, would allow us to claim that we face a discursive event based on the guidelines Pêcheux (1990) provided in Discourse: structure or event, or whether it would constitute itself as an enunciative event in the molds of what has been exploited by Indursky since 2002.

Keywords: Discursive event. Enunciative event. Dilma Rouseff's inauguration. Discourse Analysis. 
Ercília Ana

Cazarin

Gesualda dos

Santos Rasia

O objetivo central deste texto é compreender se a posse de Dilma Rousseff na presidência do Brasil (2011) constituiu-se ou não em um acontecimento discursivo. ${ }^{1}$ A questão que nos instiga é buscar compreender se o fato de Dilma ter sido a primeira mulher a ocupar o lugar da presidência da República, revestido de características que entendemos singulares, nos permitiria afirmar que estaríamos diante de um acontecimento discursivo nos moldes do que preceitua Pêcheux (1990) em Discurso: estrutura ou acontecimento, ou se estaríamos apenas diante de um acontecimento enunciativo nos moldes do que vem sendo trabalhado por Indursky desde 2002.

Para sustentar teoricamente a análise proposta, cremos ser interessante registrar que, quando nos referimos a fatos e acontecimentos históricos, partimos do princípio de que, em Análise do Discurso (AD), o que interessa não é o acontecimento em si, o evento empírico; o que interessa é o acontecimento tomado enquanto fato histórico, resultado de uma interpretação - o fato histórico, como afirma Le Goff (1996), já é uma construção que atesta a história como prática social e, por conseguinte, sua não neutralidade. Reconhecemos, no entanto, que um acontecimento em si pode ocorrer independentemente do sujeito, mas só se torna fato histórico quando por ele simbolizado. Acreditamos, também, que acontecimentos em si, mesmo que negligenciados pelos historiadores, como afirma Le Goff (1996, p. 11), na perspectiva da AD, são entendidos no sentido de que essa negligência é também ela resultado de um gesto interpretativo, pois o "esquecimento" e/ou o silêncio também significam. De qualquer forma, neste texto, o acontecimento em si, tomado como fato histórico, é o que concebemos como acontecimento histórico, como algo pontual, capaz de gerar múltiplas discursividades, muito embora, dado à incompletude do discurso, um acontecimento, na maioria dos casos, já é resultado de uma discursividade anterior, de uma construção discursiva.

Nessa perspectiva, a posse de Dilma, em si, é tomada como fato/ acontecimento histórico. O que resta compreender é se o mesmo constitui ou não um acontecimento discursivo. Pêcheux (1990), ao tratar do discurso como estrutura e acontecimento, propõe "entrecruzar os caminhos do acontecimento, da estrutura e da tensão entre descrição e

1 Uma primeira versão deste artigo foi apresentada no Seminário da Abralin, 2013, realizado em Natal, RN. 
interpretação" e nos leva a entender que o acontecimento discursivo é consequência do acontecimento histórico que passa a ser discursivizado "no ponto de encontro de uma atualidade e de uma memória" (p. 17). Dito diferentemente: o acontecimento discursivo é que permite a inscrição do acontecimento histórico no interdiscurso. Um acontecimento discursivo estabelece uma ruptura (rompe com a "estabilidade" anterior) e inaugura uma nova "estabilidade" discursiva, mas não logicamente organizada, pois a mesma tem a ver com a ordem do discurso que joga com a materialidade linguística e a materialidade histórica.

Nossa hipótese é que, diferentemente da posse de Lula em 2003, segundo Indursky (2003), um acontecimento discursivo, a posse de Dilma, ainda que instaure uma reorganização de saberes, não chega a estabelecer uma ruptura no discurso a ponto de instaurar um acontecimento

As noções de acontecimento enunciativo e de acontecimento discursivo discursivo. Procurando sustentar esse entendimento, vale lembrar que, na chamada "Era Lula", Dilma Rousseff exerceu o cargo de Ministra de Minas e Energia e também de Ministra-Chefe da Casa Civil do governo. Foi a partir de sua atuação nesses cargos que ela se tornou nacionalmente conhecida como "a mãe do PAC" (Programa de Aceleração do Crescimento), chegando a ser indicada, como "afilhada" do ex-presidente Lula, para ser a candidata do Partido dos Trabalhadores (PT) à presidência do país. Esse é um dos fatos que sinalizam não para um rompimento do discurso e sim para sua continuidade. Ou seja, o discurso de Dilma inscreve-se na mesma formação discursiva (FD) em que estava inscrito o discurso do Governo Lula. Para efeitos metodológicos, denominamos essa formação discursiva como "FD da Era Lula". É nessa FD que ela está inscrita quando assume a presidência do país e do lugar institucional de Presidenta da República passa a enunciar, significando-se enquanto sujeito, ao significar ou (res)significar seu dizer. Ressaltamos o fato de que, no acontecimento histórico de sua posse, não temos a presença de um "enunciado coletivo"; não temos também a ruptura necessária para que ocorra o acontecimento discursivo. Por outro lado, temos diferenças que vão reorganizar os saberes da FD, marcar a instituição de uma nova posição-sujeito e nos colocar diante de um acontecimento enunciativo. Observemos a sequência discursiva de referência (SDR) que se segue.

SDR 1

[...] Pela decisão soberana do povo hoje será a primeira vez que a faixa presidencial cingirá o ombro de uma mulher. Sinto uma imensa honra 
Ercília Ana

Cazarin

Gesualda dos

Santos Rasia

196 por essa escolha do povo brasileiro e sei do significado histórico dessa decisão. [...] tenho comigo a força e o exemplo da mulher brasileira. Abro meu coração para receber neste momento uma centelha da sua imensa energia e sei que meu mandato deve incluir a tradução mais generosa dessa ousadia do voto popular que após levar à Presidência um homem do povo, um trabalhador, decide convocar uma mulher para dirigir os destinos do País [...]. (Pronunciamento de posse, grifos nossos).

Destacamos dessa SDR: “Pela decisão soberana do povo hoje será a primeira vez que a faixa presidencial cingirá o ombro de uma mulher." Na nossa compreensão, essa sequência discursiva de referência sinaliza para uma posição-sujeito diferente da de Lula, e isso pode ser constatado nos modos como a materialidade linguística dá corpo para a discursividade. Atente-se, por exemplo, para o fato de que a expressão definida um homem é expandida via predicações: um homem do povo, um trabalhador. Essas expansões mobilizam a memória histórica da trajetória de Lula como operário e o que representou sua chegada ao poder. Em contrapartida, a expressão definida uma mulher, referida à Presidenta Dilma, compõe-se pela lacunaridade, em contraste aos lugares de preenchimento possíveis. Essa suspensão não instaura o antagonismo, visto que o elemento mulher pode ser partícipe tanto da categoria povo quanto da de trabalhador. Soa como se desnecessário fosse dizer; tratase, antes, de uma ampliação do espectro. Contudo, a ausência, enquanto deixar de dizer, faz com que a categoria de gênero reste em relevo. Por essa razão, é possível dizer que é continuidade, mas também diferença, porque temos ele, um homem do povo, um trabalhador compromissado com os trabalhadores em geral; e ela, embora afinada com o Governo Lula, marca sua posição enquanto mulher. Por isso, entendemos que a Presidenta Dilma enuncia da mesma FD, mas de outra posição-sujeito.

Ainda procurando enfatizar a não ruptura do discurso, apresentamos, na continuidade do texto, outras SDRs e algumas imagens que apontam para a continuidade, mas também para a diferença do discurso, e não para a ruptura. $O$ interesse de apresentar as imagens fotográficas tem a ver com as mudanças ocorridas no campo do discurso político nas últimas décadas. Orlandi (1999), ao tratar da questão da metodologia em $\mathrm{AD}$, escreve que o analista pode mostrar o trabalho da ideologia, observar os efeitos da língua na ideologia e apreender a historicidade do texto. Entendemos que isso também pode ocorrer 
quando se trata de imagens, concebidas como materialidade de discurso. Nessa perspectiva, ancoramo-nos em Pêcheux (1999, p. 51) quando aponta que "a negociação entre o choque de um acontecimento histórico singular e o dispositivo complexo de uma memória poderia bem, com efeito, colocar em jogo a nível crucial uma passagem do visível nomeado, na qual a imagem seria um operador de memória social". Assim, além da importância da AD no processo de restituição da espessura histórica da discursividade, precisamos considerar também as imagens, os recursos disponibilizados pela mídia, imagens e recursos estes que, antes de se constituírem gestos de interpretação do analista, são já gestos de interpretação da própria mídia, na medida em que resultam de recortes seletivos relacionados a injunções na ordem do dizer/mostrar. A inscrição da campanha eleitoral de Dilma Rousseff na herança política de Lula nunca foi fato omitido para a mídia e muito menos pela mídia.

Courtine (2006) assinala que seria interessante que a Análise do Discurso administrasse suas análises considerando discursos, imagens e práticas. Segundo ele,

[...] a transmissão da informação política, atualmente dominada pelas mídias, se apresenta como um fenômeno total de comunicação, representação extremamente complexa na qual os discursos estão imbricados em práticas não verbais, em que o verbo não pode mais ser dissociado do corpo e do gesto, em que a expressão pela linguagem se conjuga com a expressão do rosto, em que o texto torna-se indecifrável fora de seu contexto, em que não se pode mais separar linguagem e imagem. (p. 57).

Levando em conta as ponderações até aqui feitas, apresentamos mais uma sequência discursiva de referência do pronunciamento de posse da Presidenta Dilma e, logo a seguir, uma foto representativa do evento histórico-discursivo em pauta (Figura 1).

SDR 2

[...] Venho, antes de tudo, para dar continuidade ao maior processo de afirmação que este país já viveu. Venho para consolidar a obra transformadora do presidente Luís Inácio Lula da Silva, com quem tive a mais vigorosa experiência política da minha vida e o privilégio de servir ao país, ao seu lado, nestes últimos anos. De um presidente que mudou a 
Ercília Ana

Cazarin

Gesualda dos

Santos Rasia

198

forma de governar e levou o povo brasileiro a confiar ainda mais em si mesmo e no futuro do seu País. A maior homenagem que posso prestar a ele é ampliar e avançar as conquistas do seu governo. Reconhecer, acreditar e investir na força do povo foi a maior lição que o presidente Lula deixou para todos nós. Sob sua liderança, o povo brasileiro fez a travessia para uma outra margem da história. Minha missão agora é de consolidar esta passagem e avançar no caminho de uma nação geradora das mais amplas oportunidades. (Pronunciamento de posse).

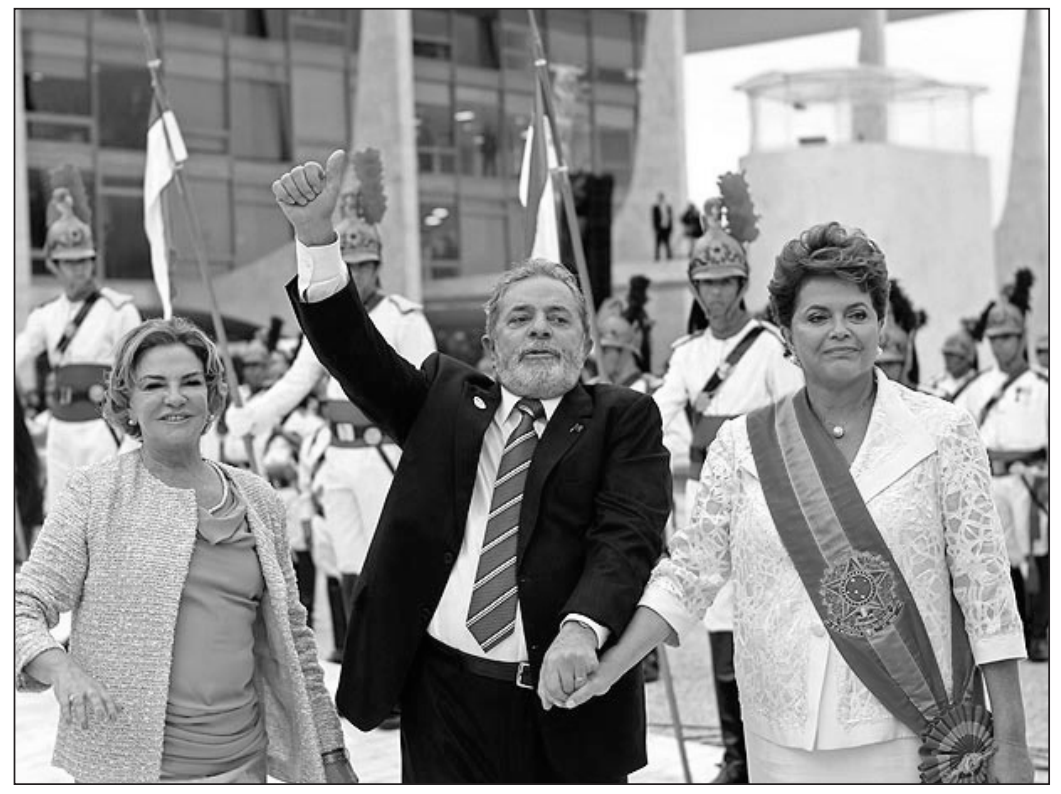

Figura 1 - Posse de Dilma Rousseff (jan./2010)

Fonte: <http://noticias.terra.com.br/brasil/politica/veja-fotos-da-cerimonia-de-possede-dilma-rousseff,bf4897730cbda310VgnCLD200000bbcceb0aRCRD.html>.

A SDR 2 e a imagem recém-apresentadas nos permitem compreender que o governo da Presidenta Dilma é uma continuidade do Governo Lula. Para tanto, mais uma vez nos reportamos aos pontos de encontro tecidos entre a materialidade linguística e a histórica, os quais agrupamos em dois conjuntos: aqueles que se referem, na voz da Presidenta, à projeção de seu governo e aqueles que reportam à evocação dos feitos de Lula. o primeiro conjunto tem como sinalizadores verbos e expressões que remetem, em seu conjunto, à solidificação e avanço do mesmo "dar continuidade", "consolidar"; "ampliar e avançar as conquistas do seu governo"; "consolidar esta passagem e 
avançar no caminho". Com relação ao segundo conjunto, há qualificações atribuídas ao Presidente Lula, direta e indiretamente colocadas, se olhadas do ponto de vista sintático "o maior processo de afirmação que este país já viveu”; “obra transformadora”; "um presidente que mudou a forma de governar e levou o povo brasileiro a confiar ainda mais em si mesmo e no futuro do seu País"; "Reconhecer, acreditar e investir na força do povo foi a maior lição que o presidente Lula deixou para todos nós"; "Sob sua liderança, o povo brasileiro fez a travessia para uma outra margem da história".

Vale dizer que a referência aos feitos e qualificações de Lula encontra-se, na SDR 2, em proporção maior que as projeções da Presidenta Dilma, o que não se trata apenas de uma questão de quantificação, mas de valoração mesmo, movimento este reforçado, inclusive, pelo adjunto

As noções de acontecimento enunciativo e de acontecimento discursivo adverbial que dá entrada para a enunciação: "Venho, antes de tudo...".

Os excertos de discurso destacados simbolizam e são representativos da não ruptura com a estabilidade anterior e, além disso, produzem efeito de sentido de pertencimento, de responsabilidade para com um legado histórico.

Ainda com o desejo de continuar demarcando a diferença entre os acontecimentos discursivo e enunciativo, apresentamos as imagens que se seguem por entender que elas nos permitem a compreensão de uma importante diferença existente no comportamento do povo nesses dois momentos. A figura 2, referente à posse de Lula, dá-nos a dimensão da ruptura - o povo "toma conta" da esplanada dos ministérios adentrando no lago, algo jamais visto e talvez nem imaginado -, gesto que materializa uma "nova era" é o povo chegando ao poder! Na figura 3 (na posse de Dilma), o povo também está lá, mas a performance é outra não "invadem" o lago, não sobem no mastro da bandeira... Ao contrário, é um povo satisfeito, feliz, mas “bem comportado"! A ruptura já havia acontecido!

Reiteramos a leitura que fazemos em relação a essas duas imagens. Na posse de Lula (2003), o povo, no seu imaginário, considerase "chegando lá", considera-se com o direito de ocupar a esplanada, o lago... - a imagem se constitui como discurso, ou seja, materializa o discurso que estabelece a ruptura, o que não ocorre na posse de Dilma. Nesta, conforme mostra a figura 3, há um retorno para a estabilização anterior à Era Lula. 
Ercília Ana

Cazarin

Gesualda dos

Santos Rasia

200

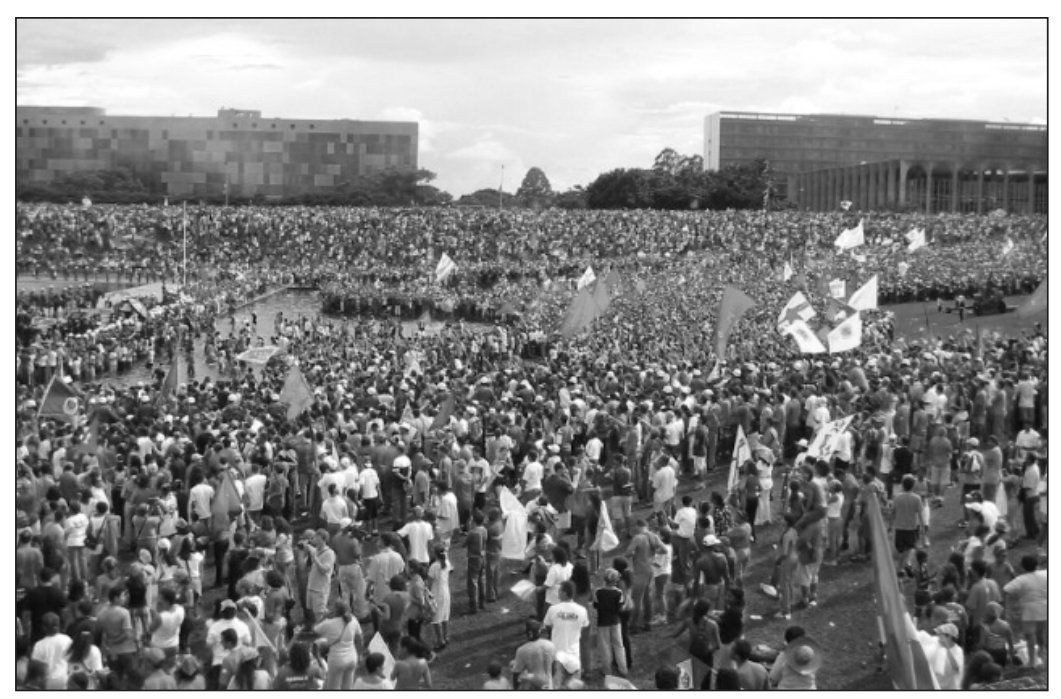

Figura 2 - 0 povo no dia da posse de Lula (2003)

Fonte: <https://www.google.com.br/search?q=fotos+de+lula+na+posse+de+2003>.

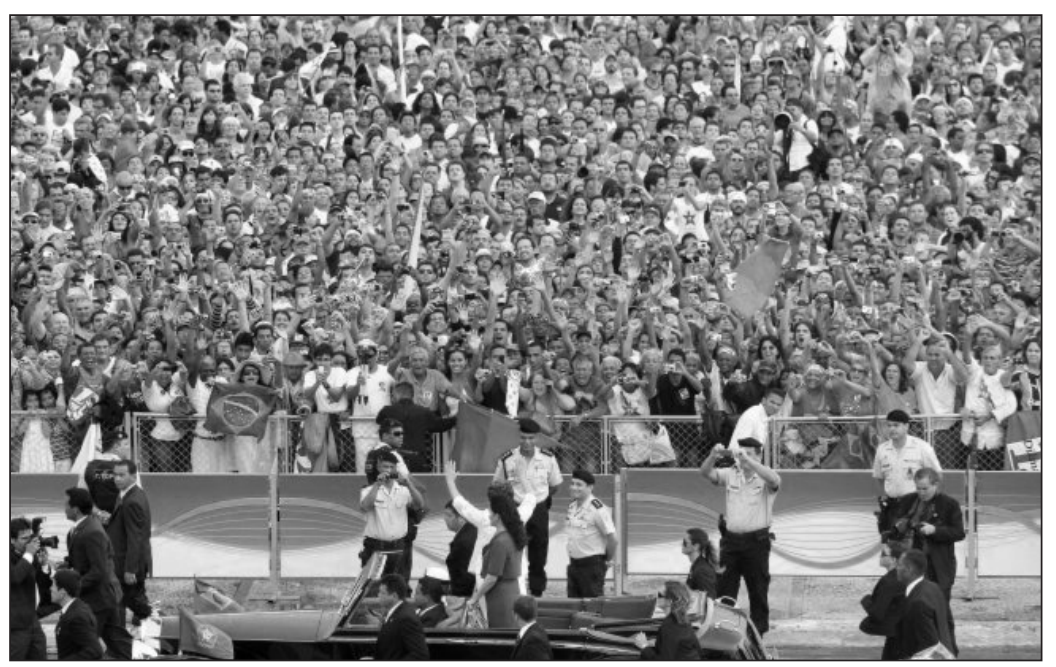

Figura 3 - 0 povo no dia da posse de Dilma (2010)

Fonte: <http://g1.globo.com/politica/posse-de-dilma/fotos/2011/01/veja-imagens-daposse-de-dilma-rousseff.html>.

Contudo, assim como a atualização da memória nem sempre faz retornarem os mesmos lugares, essa estabilização também é constituída pelo deslize. Há a cerca que segmenta o povo de sua representante maior, contudo ela não simboliza do mesmo modo que as cercas dos anos 70, por exemplo. Os sentidos por ela mobilizados são outros, 
na estabilização atual, principalmente porque já houve a "ocupação do lago". É como se a tal cerca nem mesmo precisasse estar presente, a julgar pela postura relaxada de alguns dos seguranças, os quais se permitem sorrir e até fotografar.

Entretanto, restam outras questões que merecem ser analisadas e que nos ajudam a fundamentar nossa hipótese de instauração de uma nova posição-sujeito. Senão vejamos: Dilma é a primeira mulher a assumir a presidência do país; uma ex-guerrilheira, ex-presa política, torturada pela ditadura militar, fatos esses rememorados em seu discurso de posse.

As noções de acontecimento enunciativo $e$ de acontecimento discursivo

SDR 3

[...] Reafirmo que prefiro o barulho da imprensa livre ao silêncio das ditaduras. Quem, como eu e tantos outros da minha geração, lutamos contra o arbítrio e a censura, somos naturalmente amantes da mais plena democracia e da defesa intransigente dos direitos humanos, no nosso País e como bandeira sagrada de todos os povos. [...] Dediquei toda a minha vida à causa do Brasil. Entreguei minha juventude ao sonho de um país justo e democrático. Suportei as adversidades mais extremas infligidas a todos que ousamos enfrentar o arbítrio. Não tenho qualquer arrependimento, tampouco ressentimento ou rancor. Muitos da minha geração, que tombaram pelo caminho, não podem compartilhar a alegria deste momento. Divido com eles esta conquista, e rendo-lhes minha homenagem. (Pronunciamento de posse).

Reafirmamos que os fatos recém-referidos provocam uma reorganização de saberes deslocam, reelaboram e/ou (res)significam sentidos. Nesses movimentos, reconfiguram-se os saberes da formação discursiva em pauta, compondo sua heterogeneidade, a partir desses diferentes lugares de pertencimento, lugares os quais, a depender do gesto de interpretação em tela, poderiam constituir-se objeto de estudo; contudo, acreditamos que nenhum deles estaria em confronto/dissenso com a inscrição na ordem dos saberes que diz sobre a chegada de um(a) trabalhador(a) ao poder, mote esse sustentador do que designamos de FD da Era Lula (Figura 4). 


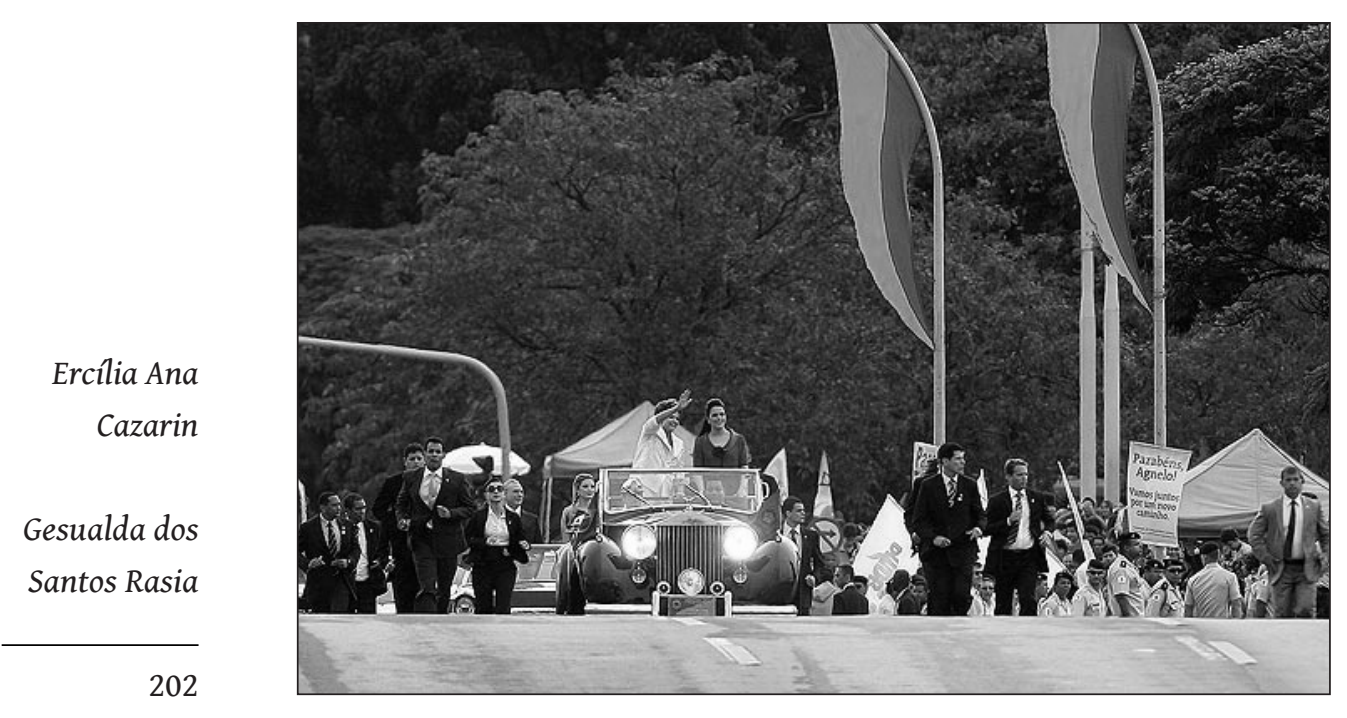

Figura 4 - Desfile de posse (2010)

Fonte: <http://noticias.terra.com.br/brasil/politica/veja-fotos-da-cerimonia-de-possede-dilma-rousseff,bf4897730cbda310VgnCLD200000bbcceb0aRCRD.html>.

Os fatos e imagens apresentados até aqui, com certeza, não são corriqueiros na vida de um país como o nosso e, a partir deles, discursividades distintas emergem. Acrescente-se ainda: uma mulher que, no dia da posse, desfila em carro aberto ao lado da filha, e não do marido, constitui-se algo que até então jamais ocorrera.

O entrelaçamento entre o pronunciamento de Dilma e as imagens da posse simboliza novos tempos, novos valores sociais que mexem com a estabilidade discursiva. No entanto, no nosso entendimento, não há como sustentar um acontecimento discursivo, pois esses novos saberes não rompem com a estabilidade anterior - apenas se diferenciam dela em alguns aspectos, o que nos autoriza a falar no estabelecimento de novos sítios de significância dentro da mesma FD. Diferente foi o caso da posse do ex-presidente Lula (2003), em que o Lula-lá, almejado e repetido durante muitos anos, se (res)significa em enunciados que podem, entre outros, ser parafraseados por "chegamos lá", "o povo chega ao poder", "Lula está lá" etc., concretizando um acontecimento discursivo:

[...] Lula lá não era mais um sonho, um objeto inalcançável de desejo, uma utopia, um impossível. E foi exatamente esta transformação, que levou da utopia à realidade, que produziu o acontecimento. Naquela noite de 27 de outubro de 2002, fomos 
testemunhas de um acontecimento histórico que clamava por discurso, que reclamava sentidos, por novos sentidos, sentidos ainda não ditos, desconhecidos. [...] a multidão se movia, se reunia, gritava, cantava. Comemorava e, ao mesmo tempo, rememorava. [...] Assistíamos a algo ainda não presenciado anteriormente, a algo ainda não nomeado na cena política brasileira. $\mathrm{E}$ este novo, este inusitado construía a ruptura com o mesmo [...]. E esta ruptura colocava pela primeira vez, nesses 500 anos de história, na Presidência da República Federativa do Brasil, um filho do povo. [...] Um homem que se chama apenas Silva. [...] E esta ruptura certamente produz um acontecimento discursivo... (INDURSKY, 2003, p. 110).

As noções de acontecimento enunciativo e de acontecimento discursivo

Essa citação de Indursky nos leva a Pêcheux, em especial, quando ele enfatiza que a materialização discursiva de um acontecimento discursivo ocorre por meio de um "enunciado coletivo" que instaura a ruptura e, ao mesmo tempo, provoca o confronto discursivo. Pêcheux (1990) pondera que um acontecimento discursivo desestabiliza o que está posto e provoca um novo vir a ser, reorganizando "o espaço da memória que ele convoca e que já começa a reorganizar" (p. 19). Quando Pêcheux refere-se ao "espaço da memória que ele convoca", registra que um acontecimento discursivo, concomitantemente, funciona como "uma interrupção e como uma emergência". Essa emergência pode ser observada nas imagens da posse de Lula (2003), apresentadas nas capas da revista Isto É (Figura 5) e da revista Época (Figura 6), entre outras.

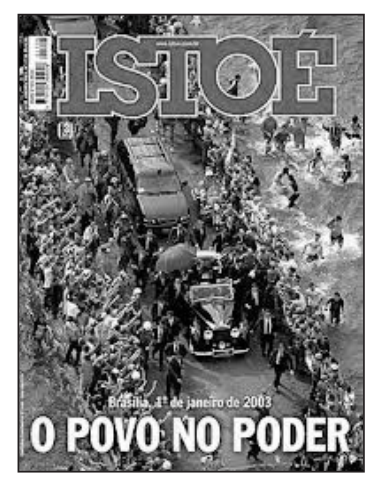

Figura 5 - Capa da Isto É (jan. 2003) 
Ercília Ana

Cazarin

Gesualda dos

Santos Rasia

204

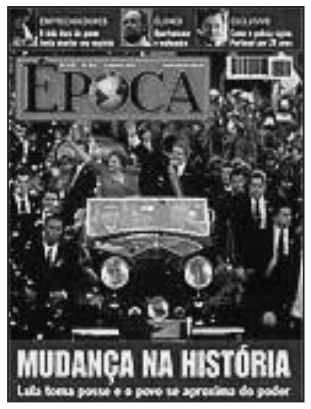

Figura 6 - Capa da Época (jan. 2003)

Tanto as imagens, em AD, entendidas como uma das formas de materialização do discurso quanto os enunciados "O povo no poder" e "Mudança na história" nos levam a compreender a emergência de novos sentidos que imediatamente são gerados pelo acontecimento discursivo, instaurado pela posse de Lula; levam-nos também à apreensão da representação do político e, por conseguinte, do confronto que, desde logo, aí se estabelece.

Interessa registrar que, em $\mathrm{AD}$, o político é concebido como relações de força, de poder que se materializam na e pela cena discursiva. Diferente é o caso das imagens de capa quando da posse de Dilma, as quais não simbolizam ruptura, mas apontam diferenças (Figuras 7 e 8).

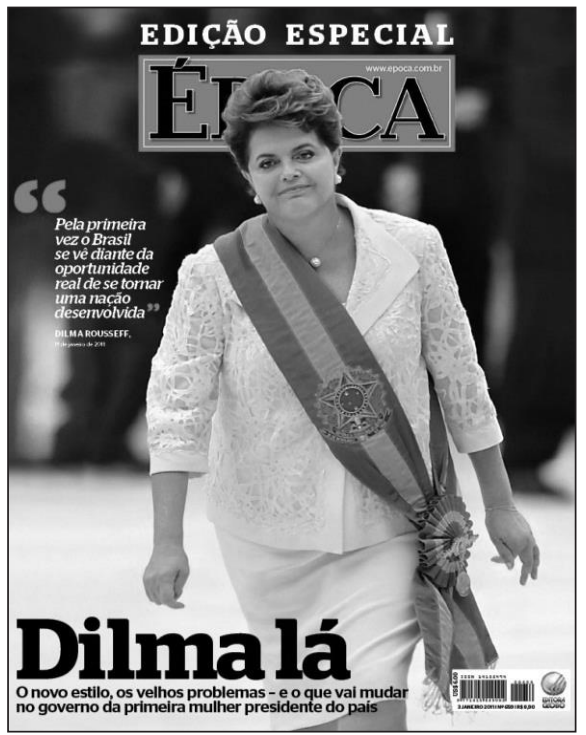

Figura 7 - Revista Época (3 jan. 2011) 


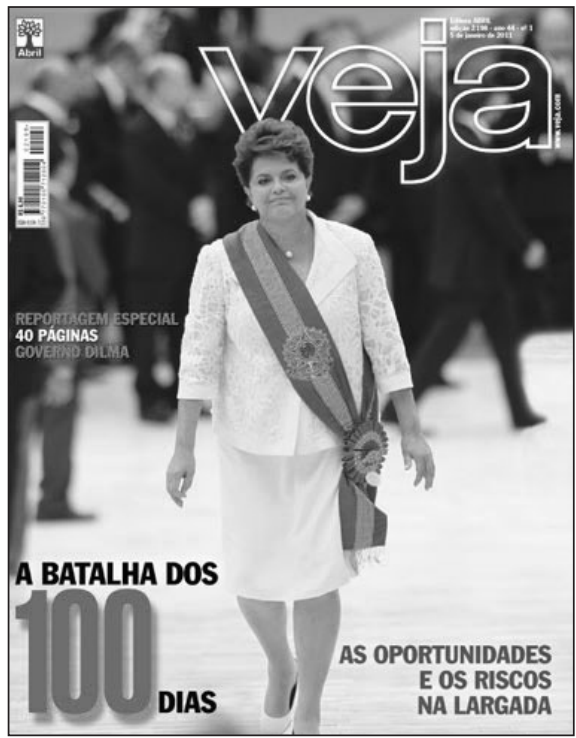

As noções de acontecimento enunciativo e de acontecimento discursivo

Figura 8 - Revista Veja (5 jan. 2011)

Ainda tentando explicitar os efeitos de sentido produzidos pelo acontecimento histórico da posse de Dilma, voltamos à citação de Indursky, para nos perguntar se o fato de, pela primeira vez, nesses quinhentos anos de história, na presidência da República Federativa do Brasil, uma mulher assumir o cargo de presidenta nos levaria a entender a ocorrência de um acontecimento discursivo. Entendemos que, se estivéssemos realizando uma análise do discurso feminista, talvez pudéssemos pensar em uma ruptura capaz de se constituir em um acontecimento discursivo, mas não é o caso em análise neste texto.

$\mathrm{E}$, vale lembrar, a fase inaugural da história do feminismo, no final do século XIX, é marcada pelos movimentos em torno da luta pelo direito de voto à mulher. A questão do gênero emerge a partir da convergência para uma questão que é essencialmente política.

Nossa análise elege o campo do político e tem a ver com a formação discursiva na qual estavam inscritos os saberes do Governo Lula, que, metodologicamente, estamos denominando de "FD da Era Lula". Atente-se para o modo como a manchete faz ressoar o bordão da Era Lula, em "Dilma lá", presentificando uma memória e, por extensão, a filiação à ordem de saberes da referida FD. É a partir dessa FD que Dilma passou a enunciar quando fez parte do Governo Lula e também quando assumiu a função de enunciar do lugar institucional da presidência do país. 
Ercília Ana

Cazarin

Gesualda dos

Santos Rasia

206

Entendemos que o fato de enunciar desse lugar, politicamente, não a "desfilia" da referida FD, apenas a inscreve em uma outra posição-sujeito. Entre muitas passagens do pronunciamento de posse, observemos a SDR a seguir, que nos possibilita a compreensão dessa nova posição-sujeito da qual Dilma, na função enunciativa de presidenta do país, passa a enunciar.

\section{SDR 4}

[...] Venho para abrir portas, para que muitas outras mulheres também possam, no futuro, ser presidentes e para que, no dia de hoje, todas as mulheres brasileiras sintam o orgulho e a alegria de ser mulher. Não venho para enaltecer a minha biografia, mas para glorificar a vida de cada mulher brasileira. Meu compromisso supremo, reitero, é honrar as mulheres, proteger os mais frágeis e governar para todos [...]. (Pronunciamento de posse).

Essa nova função enunciativa assumida na presidência do país, sem dúvida, faz Dilma reorganizar seu dizer "Disse, no início deste discurso, que eu governarei para todos os brasileiros e brasileiras. E vou fazê-lo." Aqui, assim como na discursividade engendrada pelas imagens das capas, aliadas aos enunciados, a questão feminina é uma entre outras tantas; decididamente, não é a central. Vale dizer que o fato de Dilma ser a primeira mulher a ocupar a presidência da República no Brasil produz efeitos de sentido peculiares, os quais, para serem apreendidos enquanto gesto de análise, demandariam o recorte de outras discursividades, para além do pronunciamento de posse. Por exemplo, o alcance político do compromisso com as mulheres, simbolizado na opção, de parte da presidenta, pelo uso da marca de feminino no substantivo que a nomeia.

Observemos outra passagem:

SDR 5

[...] Para dar longevidade ao atual ciclo de crescimento é preciso garantir a estabilidade de preços e seguir eliminando as travas que ainda inibem o dinamismo de nossa economia, facilitando a produção e estimulando a capacidade empreendedora de nosso povo, da grande empresa até os pequenos negócios locais, do agronegócio à agricultura familiar. (Pronunciamento de posse). 
Nesses excertos, estão presentes marcas linguísticas “dar longevidade ao atual ciclo de crescimento [...] garantir a estabilidade de preços [...] seguir eliminando [...] -, marcas estas que atestam a continuidade do discurso e não a ruptura.

Por outro lado, interessa observar que a Presidenta Dilma, compromissada com os mais frágeis, afinada com o Governo Lula, marca sua posição enquanto mulher e explicita seu compromisso com as mulheres de seu país. Trata-se da diferença, mas instaurada no interior do mesmo, atente-se, por exemplo, para o modo como as capas linearizam a questão do gênero, que aparece, contudo, lateralmente, não é a questão central.

Diante do que apresentamos até aqui, nosso entendimento é o de que, no caso da posse de Dilma, estaríamos frente a um acontecimento enunciativo a partir do qual saberes e sentidos se movimentam, se As noções de acontecimento enunciativo e de acontecimento discursivo (re)organizam, provocam novos efeitos de sentido, mas não a ponto de instaurar uma ruptura, no dizer de Pêcheux, "fundacional", no sentido de que, ao romper, instaura o "novo". Para melhor explicitar o que estamos entendendo como acontecimento enunciativo, recorremos a Indursky (2008, p. 28-29):

[...] o acontecimento enunciativo implica apenas a instauração de uma nova posição-sujeito no interior de uma mesma FD. Dito de outra maneira: surge aí uma nova fragmentação em relação à forma-sujeito, ou seja, surge aí um novo modo de enunciar os sentidos desta formação discursiva, mas este novo modo não opera pelo viés da ruptura com a formação discursiva e com a forma-sujeito. [...] Surgem novos saberes no interior da mesma FD. Enquanto o acontecimento discursivo remete para fora, é externo à FD que lhe dá origem, instaurando um novo sujeito histórico, o acontecimento enunciativo provoca a fragmentação da forma-sujeito e se dá, por conseguinte, no interior da própria formação discursiva. (grifos do autor).

Reiteramos, portanto, a distinção entre acontecimento discursivo e acontecimento enunciativo: o primeiro determina o surgimento de uma nova FD e, por conseguinte, de uma nova forma-sujeito;

2 Ressaltamos que fundacional não pode ser confundido com fundador, pois o primeiro é da ordem do empírico, e o segundo é afetado pelo discurso. 
Ercília Ana

Cazarin

Gesualda dos

Santos Rasia

208 nele "a ruptura é radical e definitiva". O segundo se constitui apenas com a instauração de uma nova posição-sujeito no interior de uma mesma FD; surge um novo modo de enunciar os sentidos, novos saberes, provenientes de outro lugar, emergem, mas "esse novo modo não opera pelo viés da ruptura; seu funcionamento se dá pelo viés da tensão e do estranhamento", instaurando o que entendemos como diferença e/ou divergência entre posições-sujeito que não são iguais, mas convivem em um mesmo domínio de saber e se apresentam como distintas maneiras de se relacionar com a forma-sujeito e com a ideologia.

Para sintetizar, a partir do escrito por Indursky (2008), entendemos que um acontecimento histórico gera um acontecimento enunciativo quando não provoca uma ruptura capaz de instaurar uma nova discursividade, nem faz com que o sujeito migre para outra $\mathrm{FD}^{3}$; o acontecimento enunciativo reorganiza/reestrutura a discursividade interna da FD, instituindo um "novo modo de lidar com a ideologia, sem que haja o rompimento com o domínio de saber" (INDURSKY, 2008, p. 25) - é isso que, neste texto, estamos concebendo como acontecimento enunciativo.

Por último, na tentativa de amarrar a discussão proposta neste texto, retomamos a indagação que fizemos no início: a posse de Dilma Rousseff na presidência do país (2011) se constituiu como um acontecimento discursivo ou enunciativo? Não temos dúvidas sobre o fato de que a posse da Presidenta Dilma se constituiu como um acontecimento histórico. Muito embora esse acontecimento tenha provocado "um novo modo de enunciar sentidos" e instaurado a (re)organização do discurso, no sentido de agregar novos saberes e de rememorar outros, a partir do exercício de análise realizado, entendemos que a referida posse não se constituiu como um acontecimento discursivo, pelo menos nos moldes do que preceitua Pêcheux, que é o que nos propusemos

3 Isso tem a ver com o que, em $\mathrm{AD}$, entendemos como o processo de identificação/desidentificação do sujeito. Pêcheux (1988, p. 215-217), quando aborda a relação que o sujeito pode manter com sua FD, denominou de modalidades da tomada de posição: a primeira modalidade consiste em uma superposição entre o sujeito da enunciação e o sujeito universal e caracteriza o discurso do "bom sujeito"; a segunda modalidade caracteriza o discurso do "mau sujeito", discurso no qual o sujeito da enunciação "se volta" contra o sujeito universal por meio de uma "tomada de posição". Essa segunda modalidade consiste em "uma separação (distanciamento, dúvida, questionamento, contestação, revolta...)" em relação ao que diz a forma-sujeito, conduzindo o sujeito do discurso a contraidentificar-se com o saber da formação discursiva que lhe é imposta e podendo levar a uma terceira modalidade, que funciona sob o modo da "desidentificação" do sujeito enunciador, de uma formação discursiva e de sua forma-sujeito, deslocando sua identificação para outra formação discursiva e sua respectiva forma-sujeito ou, até mesmo, instituindo uma nova formação discursiva (PÊCHEUX, 1988, p. 213-217; INDURSKY, 2002). 
analisar. Instaurou, sim, um acontecimento enunciativo marcado por diferentes discursividades, mas sem romper com os saberes próprios da "FD da Era Lula".

\section{Referências}

COURTINE, Jean-Jacques. Metamorfoses do discurso político: as derivas da fala pública. Trad. de Nilton Milanez e Carlos Piovezani Filho. São Carlos: Claraluz, 2006.

As noções de acontecimento enunciativo e de acontecimento discursivo

INDURSKY, Freda. Unicidade, desdobramento, fragmentação: a trajetória da noção de sujeito na Análise do Discurso. In: MITTMANN, Solange; GRIGOLETTO, Evandra; CAZARIN, Ercília Ana (Org.). Práticas discursivas e identitárias: sujeito e língua. Porto Alegre: Nova Prova, 2008. p. 9-33.

Lula lá: estrutura e acontecimento. Organon, Porto Alegre: UFRGS, v. 17, n. 35, p. 101-121, 2003.

A noção de sujeito em análise do discurso: do desdobramento à fragmentação. In: ENCONTRO DA ANPOLL, 15., 2000, Niterói. Anais... Porto Alegre: ANPOLL, 2002. 1 CD-ROM.

A fragmentação do sujeito em análise do discurso. In: INDURSKY, Freda; CAMPOS, Maria do Carmo (Org.). Discurso, memória, identidade. Porto Alegre: Sagra Luzzatto, 2000. p. 70-81.

LE GOFF, Jacques. História e memória. Trad. de Bernardo Leitão et al. 4. ed. Campinas: Ed. da Unicamp, 1996.

ORLANDI, Eni Puccinelli. Análise de discurso: princípios e procedimentos. Campinas: Pontes, 1999.

PÊCHEUX, Michel. o discurso: estrutura ou acontecimento? Trad. de Eni Puccinelli Orlandi. Campinas: Pontes, 1990. 
Papel da memória. Trad. de José Horta Nunes. In: ACHARD, Pierre et al. Papel da memória. Campinas: Pontes, 1999. p. 49-57.

Semântica e discurso (1975). Trad. de Eni Pulcinelli Orlandi et al. Campinas: Ed. da Unicamp, 1988.

Ercília Ana
Cazarin

Gesualda dos

Santos Rasia

210 